\title{
Palliative care in universal health coverage: What about humanitarian emergency assistance?
}

\author{
Martin Schneider ${ }^{1}$
}

Received: 1 May 2018/Revised: 21 November 2018/Accepted: 24 November 2018/Published online: 30 November 2018

(c) Swiss School of Public Health (SSPH+) 2018

In 2014, the World Health Organization (WHO) confirmed by its resolution WHA67.19 that palliative care should be an integral part of universal health coverage (WHO 2014). Palliative care is defined as "improving the quality of life of patients (adults and children) and their families who are facing the problems associated with life-threatening illness, through the prevention and relief of suffering by means of early identification and correct assessment and treatment of pain and other problems, whether physical, psychosocial or spiritual." The resolution recommends that the member states of WHO integrate palliative care into their public health systems and make it accessible to their populations in need. Countries are integrating palliative care at different rates; the process tends to be particularly slow in lowand middle-income countries, but some low-income countries have set up palliative care for their patients. For example, Uganda has had palliative care in place for AIDS patients for 20 years. The Worldwide Hospice Palliative Care Alliance is mapping the evolution of palliative care.

Humanitarian medical organisations intervene in situations of natural and man-made disasters. Historically, their emergency action has aimed to save lives. They have accumulated extensive expertise on interventions for acute medical and surgical conditions (Giannou and Baldan 2009) and are now also focusing on projects that improve the quality of life of their beneficiaries, including interventions in the field of mental health and psychosocial support and gender-based violence.

This Editorial is part of the series "Young Researcher Editorial", a training project of the Swiss School of Public Health (SSPH+).

Martin Schneider

martin.schneider@sunrise.ch

1 Institute of Global Health, University of Geneva, Geneva, Switzerland
But palliative care has just started to enter the "culture" of humanitarian organisations. They began to use the term palliative care extensively during the Ebola epidemic in West Africa when they were confronted with many patients who could not be cured. While outbreaks will continue to occur, the epidemiology of diseases is shifting towards chronic conditions, even in low-income countries where disasters and armed conflicts are common. Morbidity and mortality caused by non-communicable diseases are about to overtake infectious diseases in adults, and these diseases are usually chronic. The recent Lancet Commission report on palliative care and pain relief in universal health coverage concentrates on injuries and acute conditions (Knaul et al. 2018). Humanitarian organisations are less experienced in managing chronic conditions with long courses that are steeply increasing the number of patients who need palliative care.

We still know little about how to integrate palliative care or advanced pain control into medical emergency assistance projects (Schneider et al. 2017), but the WHO is extending its guidelines on palliative care to cover emergency assistance and the new edition of the Sphere Handbook (Sphere Association 2018), a collection of recommendations and standards for humanitarian assistance, contains a chapter on palliative care.

These endeavours combined with efforts to improve availability of opioid drugs worldwide (Husain et al. 2014) will allow humanitarian emergency organisations to better prepare their staff to integrate palliative care into their clinical care. Humanitarian organisations could develop projects with palliative care, both during short interventions and in cooperation with local health services supporting the effort to extend universal health coverage to populations in areas of natural disasters or armed conflict where patients have the right to health care that includes pain management and palliative care (Cousins et al. 2004). The public health community should assist humanitarian organisations in this effort by providing expertise on 
information synthesis and health system management, and by advocating for palliative care.

\section{Compliance with ethical standards}

Conflict of interest The author has no conflict of interest. The author is a member of the Young Researcher Editorial team of the International Journal of Public Health.

\section{References}

Cousins MJ, Brennan F, Carr DB (2004) Pain relief: a universal human right. Pain 112:1-4. https://doi.org/10.1016/j.pain.2004. 09.002

Giannou C, Baldan M (2009) War surgery. International Committee of the Red Cross, Geneva. https://www.icrc.org/en/publication/ 0973-war-surgery-working-limited-resources-armed-conflictand-other-situations-violence. Accessed 10 Nov 2018
Husain SA, Brown MS, Maurer MA (2014) Do national drug control laws ensure the availability of opioids for medical and scientific purposes? Bull World Health Org 92:108-116. https://doi.org/ 10.2471/blt.13.121558

Knaul FM, Farmer PE, Krakauer EL et al (2018) Alleviating the access abyss in palliative care and pain relief-an imperative of universal health coverage: the Lancet Commission report. Lancet 391:1391-1454. https://doi.org/10.1016/S0140-6736(17)32513-8

Schneider M, Pautex S, Chappuis F (2017) What do humanitarian emergency organizations do about palliative care? A systematic review. Med Confl Surviv 33:263-272. https://doi.org/10.1080/ 13623699.2017.1409167

Sphere Association (2018) The Sphere handbook: humanitarian charter and minimum standards in humanitarian response, 4th edn. Sphere Association, Geneva

WHO (2014) Strengthening of palliative care as a component of comprehensive care throughout the life course. WHA67.19 O, Geneva

Publisher's Note Springer Nature remains neutral with regard to jurisdictional claims in published maps and institutional affiliations. 